\title{
Management of Loss of Labial Cortical Plate during Immediate Implant Placement with Guided Bone Regeneration: A Clinical and Radiological Study
}

\author{
Jacqueline Dias J*, Panwar M, Manab K and Dushyant M \\ Department of Dental Surgery and Oral Health Sciences, Armed Forces Medical \\ College, India
}

*Corresponding author: Jacqueline Jacinta Dias, Department of Dental Surgery and Oral Health Sciences, Armed Forces Medical College, Maharashtra, Email: catchme.jacinta@gmail.com

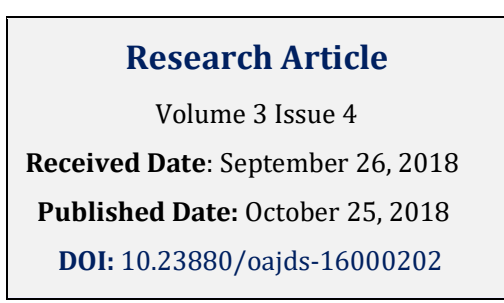

India, Tel: 9971579012;

\begin{abstract}
Background: Implant therapy has gained significant importance in rehabilitation of missing teeth in recent years. Immediate implant placement is becoming popular due to various reasons such as reduced appointments, treatment time and preservation of alveolar ridge. However, thin labial cortical plate often complicates the treatment plan in anterior region. Guided bone regeneration plays an essential role in such clinical situations.

Methods: 10 immediate implants were placed in anterior region after extraction of tooth with hopeless prognosis. Guided bone regeneration using xenograft and barrier membrane was carried out to manage labial cortical plate lost during implant placement. Cortical plate thickness and bone density was measured on CBCT at baseline and 6 months.

Results: Regeneration of lost labial cortical plate with complete coverage of exposed implant and formation of new bone was achieved in all the cases. CBCT showed an increase in labial cortical plate thickness with a mean difference of $1.36 \pm 0.18 \mathrm{~mm}$ when measured 6 months from baseline which was highly significant. It also showed statistically significant increase in bone density of new bone formed $2 \mathrm{~mm}$ apical to crest of alveolar bone in comparison to bone density of existing labial cortical plate at baseline with a mean increase of $525.33 \pm 138.56 \mathrm{HU}$.

Conclusion: Guided bone regeneration has an imperative role in replacement of missing tooth during immediate implant placement following extraction of tooth with hopeless prognosis.

Keywords: Guided bone regeneration; Labial cortical plate; Xenograft; Bone density
\end{abstract}

\section{Introduction}

Healthy anterior teeth play an important role in improving the morale and self-esteem of an individual.
Management of fractured as well as lost tooth in anterior region has always been a challenge for the clinician. Due to aesthetic concerns, prosthetic rehabilitation in anterior region turns out to be of significant importance. 
Numerous modalities are available for prosthetic rehabilitation including removable denture, fixed prosthesis and implant therapy to mention a few.

Implant therapy has become the preferred choice of treatment for tooth replacement by most of the patients. Immediate implant therapy is one of the modalities by which treatment time can be reduced. Also, immediate implant placement preserves the alveolar ridge dimensions. However, there are certain situations where placement of dental implant is challenging and require advanced surgical procedures [1,2]. Thin labial cortical plate is one such common obstacle faced during immediate implant placement in anterior region [3].

Regenerative procedures play a vital role in above clinical situations where there is inadequate or loss of soft and hard tissue. Guided bone regeneration is a procedure that uses barrier membrane to direct the osteoblasts at sites with inadequate dimensions or volume to promote new bone formation, which is essential for proper function and esthetics. This procedure is applied to encourage hard tissue formation in order to promote osseointegration of dental implants. Bone grafts used in combination with barrier membranes i.e. GBR is a reliable and validated procedure. This study demonstrates the role of guided bone regeneration in regeneration of lost labial cortical plate during immediate implant placement after extraction of a tooth with hopeless prognosis.

\section{Material and Methods}

\section{Patient Selection and Preparation}

10 patients ( 6 males and 4 females) aged between 21 and 55 years requiring extraction of anterior tooth for reasons such as caries, fractured tooth, endodontic failure etc were recruited for the study Figure 1. Smokers and individuals with systemic diseases contraindicating placement of dental implants were excluded.

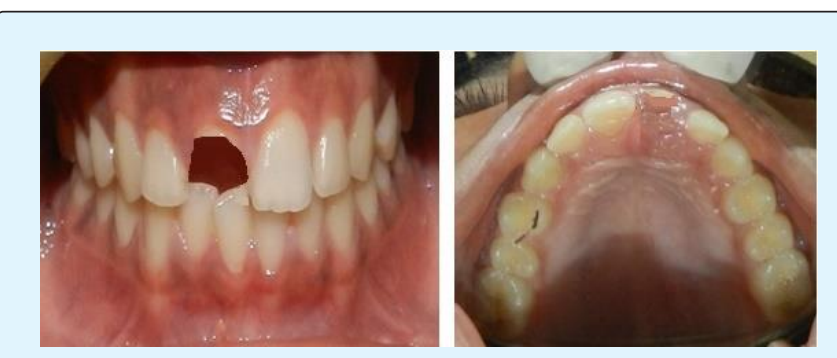

Figure 1: Fractured maxillary right central incisor indicated for extraction.
All patients were informed about the procedure and consent was obtained. Initial therapy was done and instructions were given for oral hygiene maintenance. Radiological parameters such as labial cortical plate thickness and radiological bone density $2 \mathrm{~mm}$ apical to crest of the labial bone were measured at baseline on CBCT (Figures 2 \& 3). After correlating clinical and radiographic findings, patients were planned for immediate implant followed by cement retained prosthesis.

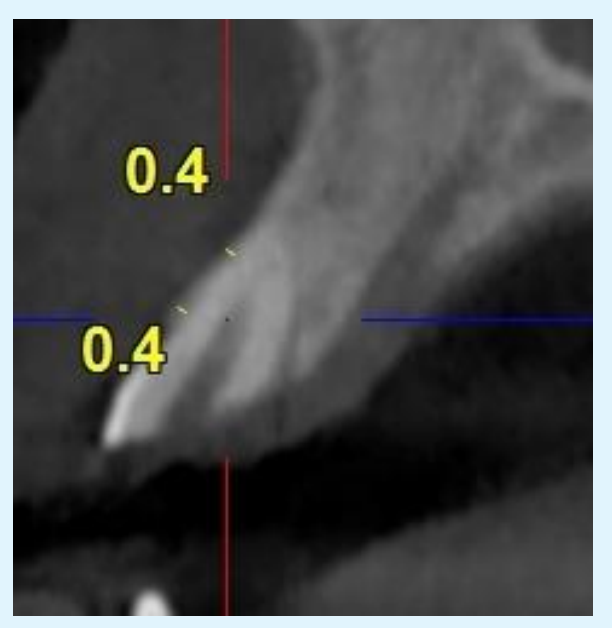

Figure 2: Extremely thin labial cortical plate as seen on CBCT at baseline.

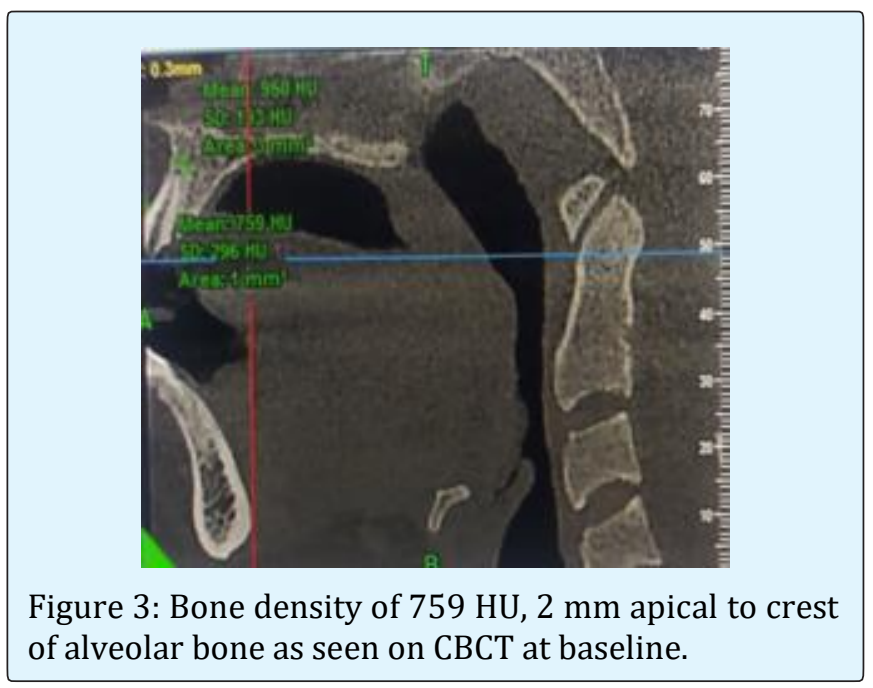

\section{Surgical Procedure}

The surgical site was anaesthetized with buccal and palatal infiltration using local anaesthesia of $2 \%$ lignocaine with 1:80,000 adrenaline. Extraction of tooth was done using periotomes (Figure 4). 


\section{Open Access Journal of Dental Sciences}

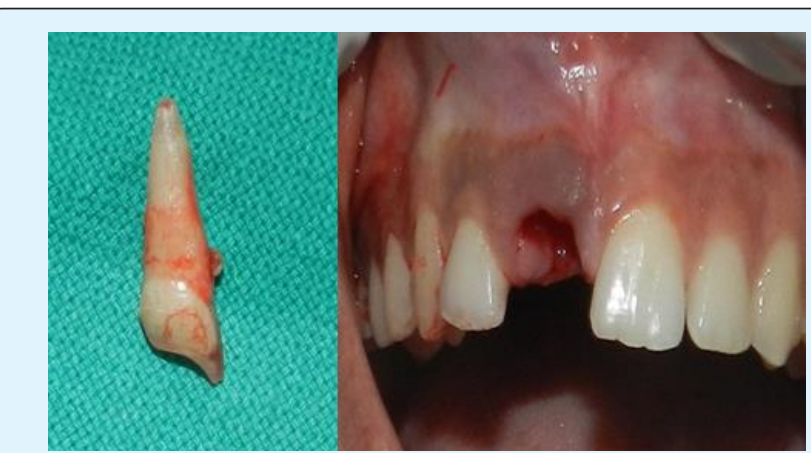

Figure 4: Atraumatic extraction of tooth with periotome.

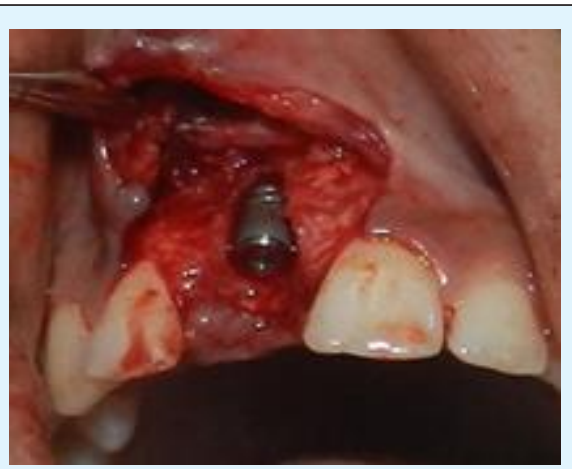

Figure 5: Loss of labial cortical plate during immediate implant placement.
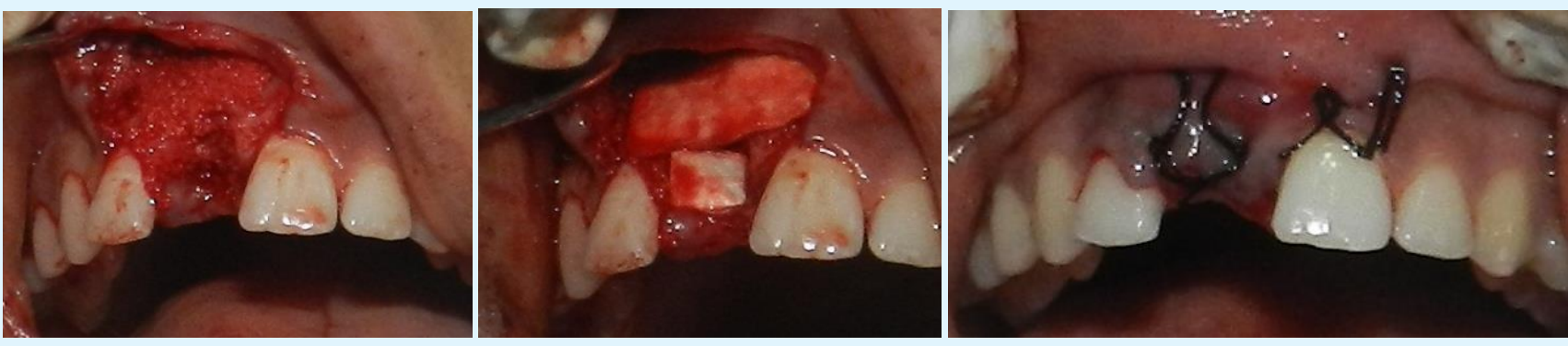

Figure 6: Guided bone regeneration with xenograft and barrier membrane.

Labial cortical plate was fractured and lost during extraction of tooth and osteotomy preparation for implant placement in all the cases Figure 5. It was ensured that adequate primary stability $(40-50 \mathrm{Ncm})$ was achieved during implant placement. Guided bone regeneration was carried out with xenograft and resorbable barrier membrane Figure 6. Patients were prescribed postoperative antibiotic and anti-inflammatory coverage i.e. Augmentin and Combiflam for 7 and 3 days respectively. Sutures were removed after 10 days.

\section{Parameters Measured}

Patients were recalled after 6 months and the length, thickness and density of labial cortical plate in relation to implant placed was assessed on CBCT (Figure 7). Data thus collected was statistically analysed according to Paired t test using SPSS version 22 software. Soft tissue in relation to implant placed was assessed for any complications (Table 1). Healing abutment was placed for 2 weeks. After 14 days, healing abutment was removed, impression made, PFM crown was fabricated and cemented.
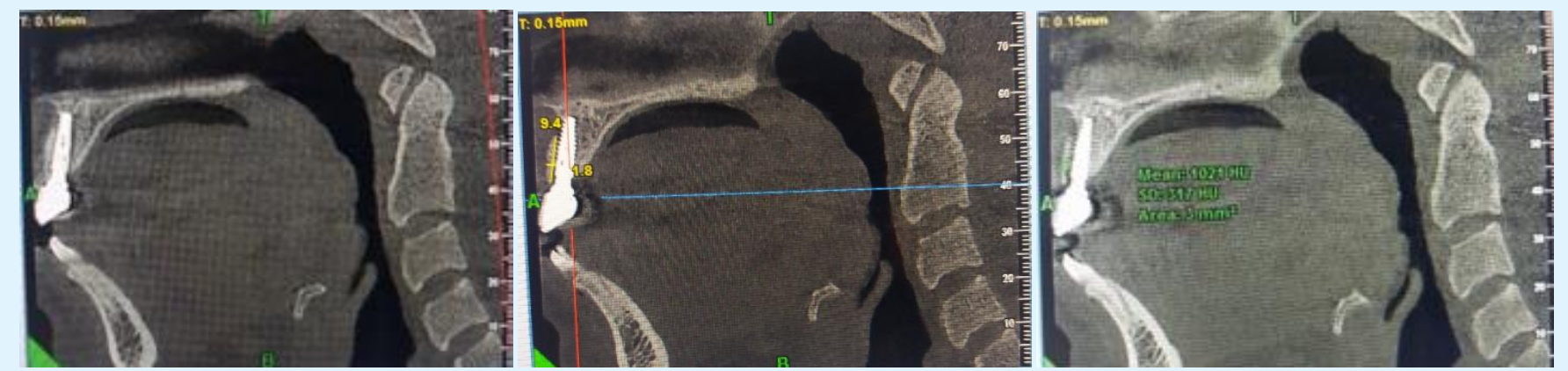

Figure 7: Complete coverage of dental implant with labial cortical plate of $1.8 \mathrm{~mm}$ thickness and bone density of 1021 HU as seen on CBCT. 


\section{Open Access Journal of Dental Sciences}

\begin{tabular}{|c|c|c|c|c|}
\hline No of Participants & Implant Success Rate & Complications & Failure & $\begin{array}{c}\text { Exposed Implant Surface } \\
\text { Coverage Post GBR }\end{array}$ \\
\hline 10 & $100 \%$ & Nil & Nil & $\begin{array}{c}\text { Complete coverage of exposed } \\
\text { implant in all cases }\end{array}$ \\
\hline
\end{tabular}

Table 1: Implant Success Rate.

\section{Result}

A total of 10 implants were placed in anterior region which included 06 males and 04 females. Healing was uneventful in all the cases with no complications. $100 \%$ success was achieved with no complications and loss of implants.

Mean labial cortical plate thickness at baseline was $0.35 \pm 0.10 \mathrm{~mm}$ and $1.71 \pm 0.23 \mathrm{~mm}$ at 6 months Table 2 . Mean bone density $2 \mathrm{~mm}$ apical to crest at baseline was
$950.83 \pm 193.35 \mathrm{HU}$ and $1476.16 \pm 125.02 \mathrm{HU}$ at 6 months Table 3 .

CBCT showed an increase in labial cortical plate thickness with a mean difference of $1.36 \pm 0.18 \mathrm{~mm}$ when measured 6 months from baseline which was highly significant Table 2. Statistical analysis also showed significant increase in bone density $2 \mathrm{~mm}$ apical to crest of alveolar bone in comparison to residual bone density with a mean increase of $525.33 \pm 138.56$ HU Table 3 .

\begin{tabular}{|c|c|c|c|c|}
\hline Parameter & $\begin{array}{c}\text { Labial Cortical Plate Thickness } \\
\text { at Baseline (M } \mathbf{\text { SD}})\end{array}$ & $\begin{array}{c}\text { Labial Cortical Plate Thickness } \\
\text { at } 6 \text { months (M } \pm \text { SD) }\end{array}$ & Difference & p Value \\
\hline Measurement $(\mathrm{mm})(\mathrm{M} \pm \mathrm{SD})$ & $0.35 \pm 0.10$ & $1.71 \pm 0.23$ & $1.36 \pm 0.18$ & $.000^{*}$ \\
\hline
\end{tabular}

M- Statistical Mean

SD - Standard Deviation

*Statistically Significant - $\mathrm{p}<0.005$

Table 2: Statistical Comparison of Labial Cortical Plate Thickness at Baseline and 06 months.

\begin{tabular}{|c|c|c|c|c|}
\hline Parameter & $\begin{array}{c}\text { Bone Density at Baseline } \\
(\mathbf{M} \pm \text { SD) }\end{array}$ & $\begin{array}{c}\text { Bone Density at 6 months } \\
(\mathbf{M} \pm \text { SD) }\end{array}$ & Difference & p Value \\
\hline Measurement (HU) (M \pm SD) & $950.83 \pm 193.35$ & $1476.16 \pm 125.02$ & $525.33 \pm 138.56$ & $.000^{*}$ \\
\hline
\end{tabular}

M- Statistical Mean

SD - Standard Deviation

*Statistically Significant - $\mathrm{p}<0.005$

Table 3: Statistical Comparison of Bone Density at baseline and 6 months.

\section{Discussion}

Presence of healthy dentition is an integral component of general physical health. Healthy anterior teeth provide better morale and self-esteem to an individual. Many treatment modalities are available for providing prosthetic replacement, of which implant therapy has gained significant popularity in past few years.

Implants have conventionally been used for rehabilitation of missing teeth. Apart from that, implant now days play a significant role in retention of maxillofacial prosthesis and as craniofacial implants. Implants are also becoming imperative in field of orthodontics as an absolute anchorage. Due to the variety of usage of implants, different modalities for applications

Jacqueline Dias J, et al. Management of Loss of Labial Cortical Plate during Immediate Implant Placement with Guided Bone Regeneration: A Clinical and Radiological Study. J Dental Sci 2018, 3(4): 000202. of implants are being developed with immediate implant being one of these.

The decision of immediate implant placement depends on various factors such as morphology of socket wall, root curvature, periapical pathology, periodontal condition of the tooth to be extracted etc. Reduced appointments, treatment time and preservation of hard and soft tissue dimensions are some of the advantages of immediate implant therapy. Apart from biological advantages, immediate implant also provides psychological benefit. The success of immediate implant depends on various factors such as proper case selection and treatment planning.

For success of immediate implant, sufficient bone thickness and volume is an important prerequisite. Labial 


\section{Open Access Journal of Dental Sciences}

cortical plate thickness depends on numerous factors such as tooth position, tooth proclination, root convexity etc. It has been demonstrated that labial cortical plate is thinnest in maxillary anterior region with a range of 0.8 $1.5 \mathrm{~mm}$ [4]. This often causes loss of labial cortical plate either during extraction or implant placement. Loss of labial cortical plate is one of the commonest complications faced by a clinician during immediate implant placement. Guided bone regeneration plays an important role in dealing with such clinical scenarios.

Concept of guided tissue regeneration was introduced by Melcher in 1976. He advocated use of barrier membrane for selective repopulation of periodontal ligament cells to promote regeneration of soft tissues. Guided bone regeneration technique is similar to guided tissue regeneration and aim at promoting selective repopulation of osteoblasts at the site. It involves use of cell occlusive membrane for space provision promoting the in growth of osteogenic cells while preventing migration of undesired cells such as epithelial cells. It also stabilises blood clot thus promoting wound healing process [5]. The membranes could be either resorbable or non-resorbable, resorbable membranes being preferred due to obvious advantage of avoiding second surgery. Absorbable collagen membranes are more frequently used in dentistry for guided bone regeneration $[6,7]$.

Bone substitute materials used in guided bone regeneration are available in different shapes and sizes. They can be autogenous, allografts, alloplasts or xenografts based on the source of origin [8]. Autogenous bone graft is still considered as ideal augmentation material as it combines osteogenic and osteoinductive properties [9]. Disadvantages of autogenous bone grafts are donor site morbidity and rapid resorption $[10,11]$. These limitations have led to increase in popularity of alloplastic grafts and xenografts. In this study xenograft was used for guided bone regeneration.

Xenografts are derived from different species such as bovine or porcine, to mention a few. Xenografts are osteoconductive in nature and act as a scaffold for the new bone formation. They are replaced by creeping substitution and have slower resorption rate than autogenous grafts thus having an added advantage [12].

Loss of labial cortical plate during extraction is one of the commonest complications that arise intra operatively during implant placement especially in anterior region. Thin cortical plate $(<0.5 \mathrm{~mm})$ is one of the many reasons, attributing towards the loss of cortical plate. Guided bone

Jacqueline Dias J, et al. Management of Loss of Labial Cortical Plate during Immediate Implant Placement with Guided Bone Regeneration: A Clinical and Radiological Study. J Dental Sci 2018, 3(4): 000202. regeneration plays an important role in such situations thus helping in rehabilitation of missing teeth. This study demonstrates management of loss of labial cortical plate during implant placement.

The significant finding of this study was complete regeneration of lost labial cortical plate and increase in thickness of regenerated bone with a mean difference of $1.36 \mathrm{~mm}$. Study also demonstrated increased density of regenerated labial cortical plate with a mean difference of $525.33 \mathrm{HU}$ as compared to baseline values. This result is consistent with study by Kuchler, et al. where 10 year clinical and radiological outcomes were evaluated after guided bone regeneration in immediate implant cases. The author demonstrated sufficient labial cortical plate formation after GBR [13].

Increase in labial cortical plate thickness and density of new bone formed was found to be statistically significant when baseline and post 6 months values were compared $(\mathrm{p}=.000)$. Both the relevant findings can be attributed to the application of guided bone regeneration technique. 18 months follow up of cases have not shown any complications Figure 8. This is consistent with study by Lekholm where good osseointegration in exposed implants managed with GBR was demonstrated in a 5 year long study [14]. Thus, this study demonstrated that guided bone regeneration results in predictable cortical plate formation with higher bone density.

\section{Conclusion}

Within the limits of the present study, loss of labial cortical plate during implant placement can be successfully managed by guided bone regeneration. Even though the data in this study is considered preliminary, it enhances the knowledge on immediate implant placement with simultaneous guided bone regeneration.

\section{References}

1. Nevins M, Mellonig JT, Clem DS III, Reiser GM, Buser DA (1998) Implants in regenerated bone: Long-term survival. Int J Periodontics Restorative Dent 18(1): 35-45.

2. Fugazzotto PA (1997) Success and failure rates of osseointegrated implants in function in regenerated bone for 6 to 51 months: A preliminary report. Int J Oral Maxillofacial Implants 12(1): 17-24.

3. Benic GI, Mokti M, Chen CJ, Weber HP, Hammerle CH, et al. (2012) Dimensions of buccal bone and mucosa 


\section{Open Access Journal of Dental Sciences}

at immediately placed implants after 7 years: a clinical and cone beam computed tomography study. Clin Oral Implants Res 23(5): 560-566.

4. Nasrin E, Niloufar D, Farinaz A, Nasrin A, Mehrdad P (2016) Correlation Between Bone and Soft Tissue Thickness in Maxillary Anterior Teeth. J Dent (Tehran) 13(5): 302-308.

5. Van Steenberghe D, Callens A, Geers L, Jacobs R (2000) The clinical use of deproteinized bovine bone mineral on bone regeneration in conjunction with immediate implant installation. Clin Oral Implants Res 11(3): 210-216.

6. Zitzmann NU, Naef R, Schärer P (1997) Resorbable versus nonresorbable membranes in combination with Bio-Oss for guided bone regeneration. Int J Oral Maxillofac Implants 12(6): 100-109.

7. Hockers $T$, Abensur D, Valentini $P$, Legrand $R$, Hämmerle CHF (1999) The combined use of bioresorbable membranes and xenografts or autografts in the treatment of bone defects around implants. Clin Oral Implants Res 10(6): 487-498.

8. Anderegg CR, Alexander DC, Freidman M (1999) A bioactive glass particulate in the treatment of molar furcation invasions. J Periodontol 70(4): 384-387.

9. Chen TW, Chang HS, Leung KW, Lai YL, Kao SY (2007) Implant placement immediately after the lateral approach of the trap door window procedure to create a maxillary sinus lift without bone grafting: a 2-year retrospective evaluation of 47 implants in 33 patients. J Oral Maxillofac Surg 65(11): 2324-2328.

10. Schlee M, Steigmann M, Bratu E, Garg AK (2006) Piezosurgery: basics and possibilities. Implant Dent 15(4): 334-340.

11. Sbordone L, Levin L, Guidetti F, Sbordone C, Glikman A, et al. (2011) Apical and marginal bone alterations around implants in maxillary sinus augmentation grafted with autogenous bone or bovine bone material and simultaneous or delayed dental implant positioning. Clinical Oral Implants Research 22(5): 485-489.

12. Hallman M, Thor A (2008) Bone substitutes and growth factors as an alternative/complement to autogenous bone for grafting in implant dentistry. Periodontol 2000 47: 172-192.

13. Lekholm U, Sennerby L, Roos J, Becker W (1996) Soft tissue and marginal bone conditions at osseointegrated implants that have exposed threads: a 5-year retrospective study. Int J Oral Maxillofac Implants 11(5): 599-604.

14. Kuchler U, Chappuis V, Gruber R, Lang NP, Salvi GE (2016) Immediate implant placement with simultaneous guided bone regeneration in the esthetic zone: 10-year clinical and radiographic outcomes. Clin Oral Implants Res 27(2): 253-257. 